Columbia Business School
Center on Japanese Economy and Business

CENTER ON JAPANESE ECONOMYAND BUSINESS

日本经汶经営研究所

Working Paper Series

June 2016, No. 350

\title{
The Regional Spillover Effects of the Tohoku Earthquake
}

Robert Dekle, Eunpyo Hong, and Wei Xie 


\title{
The Regional Spillover Effects of the Tohoku Earthquake*
}

\author{
Robert Dekle†, Eunpyo Hong; and Wei Xie ${ }^{\S}$ \\ Department of Economics, Kaprielian Hall, USC
}

February 17, 2016

\begin{abstract}
In this paper, we trace out how a decline in industrial production in one region can be propagated throughout a country. We use the model to measure how a shock to industrial production in Tohoku - owing to the Earthquake and Tsunami from 2011 - can be propagated throughout Japan. In our econometric model, regions and industries within regions are linked by specific structures and these structures discipline how the shocks are spatially propagated.
\end{abstract}

Keyword:Tohoku earthquake, regional spillovers, industrial production, dominant region, propagation of shocks

JEL Classification: R11 R15

*We thank comments from Professors Etsuro Shioji and Walker Hanlon and participants from the 2013 and 2014 Workshops at Gakushuiin Universities and USC. We thank the Center for Global Partnership for financial assistance.

†dekle@usc.edu

‡eunpyoho@usc.edu

$\S$ weixie@usc.edu 


\section{Introduction}

There is a large and growing literature relating aggregate fluctuations to idiosyncratic disturbances (Dupor (1999); Acemoglu et al. (2012)). Economic units - firms, regions, industries, etc. - are interrelated through input-output relationships or other spillovers such as technology. An idiosyncratic shock to one of the units can result in a large change in aggregate production if there are complementarities among the units such as input-output and other relationships. Whether the idiosyncratic shock can generate substantial aggregate volatility depends on the size of the initial shock, as well as the nature and strength of the linkages or the complementarities among the units.

While these linkages are potentially important, identifying plausible exogenous shocks to the individual units remains a challenge. This paper address this challenge by combining monthly industrial production data by industry and region with region-level exposure to a localized natural disaster, the Great Tohoku Earthquake of March 2011. We exploit the heterogeneous exposure of regions to the earthquake and subsequent tsunami and their interrelationships to examine how the shock to Tohoku has been transmitted throughout Japan. We find that the maximal impact of earthquake on other Japanese regions has occurred in about 6 months. From aggregating the separate regional responses, we find that the Tohoku earthquake has lowered Japan's nationwide industrial production by 6 percent in one month, 12 percent in 6 months, and 9.6 percent in 20 months.

On March 11, 2011, a devastating earthquake and tsunami hit the Tohoku and Northern Kanto regions of Japan. The damage was mostly concentrated in the Iwate, Miyagi, and Fukushima prefectures. In particular, all three prefectures were swept by the tsunami, with much of the immediate damage caused by the tsunami. In the areas impacted by the tsunami, industrial production declined by over 95 percent between March and July of 2011.

Nearly 23000 people were killed (or missing) in these prefectures; and in the days after the earthquake, about 125,000 people (or 2 percent of the three prefectures' populations) evacuated. Destruction to the capital stock was estimated to be about $\$ 180$ billion, or 10 percent of the total capital stock in the three prefectures.

The overall weight of Iwate, Miyagi, and Fukushima in Japan is small, comprising about 4 percent of both the Japanese population and GDP in 2010. Still the immediate impact of the earthquake and tsunami on Japanese aggregate production was huge, with the negative effect on aggregate GDP lingering on for a year or more. This is because these three prefectures were major producers of electronics and other intermediate parts used for production in other Japanese regions (and even the world), and the stoppage in production of these intermediate parts meant that production of the final goods in the electronics, automotive, and other industries were stalled all over Japan. For example, Tohoku accounted for 42 percent of the micro-semiconductors and 40 percent of the flat screen filters used in the Japanese production of automobiles and cell phones. 
The importance of this collapse in Tohoku intermediate input production can be seen in how Japan's aggregate GDP declined in the immediate aftermath of the earthquake. Compared to the previous quarter (before the earthquake), Japanese aggregate GDP declined by 1.9 percent in the first quarter of $2011 .^{1}$ The declines in aggregate consumption and inventories contributed 0.9 and 0.6 percent to the overall GDP decline, respectively. ${ }^{2}$ Inventories dropped sharply, as firms nationwide dug into their inventories to supply the intermediate parts - disrupted by the earthquake - necessary for production.

In subsequent quarters, while consumption recovered, inventories continued their depletion. Between the last quarter of 2010 and the third quarter of 2012, aggregate GDP grew by 0.5 percent. Aggregate consumption contributed 1.2 percent to this growth, but the depletion of inventories and the decline in net exports contributed to dragging down GDP by 0.6 percent and 1.8 percent between the last quarter of 2010 and the third quarter of 2012. ${ }^{3}$ Exports declined as production slowed and imports rose because of the need for raw materials and construction materials for the reconstruction.

In this paper, we trace out how a decline in industrial production in one region can be propagated throughout Japan. We consistently estimate separate conditional error correction models for different regions of Japan, which we then solve for a full set of spatio-temporal impulse response functions. Conditional impulse response analysis traces out the effects of shocks over time. However, with a spatial dimension, dependence is both spatial and temporal. In our impulse responses using our econometrically estimated model, we trace out the effects from a shock to Tohoku.

In our econometric model, regions and industries within regions are linked by a well defined structure and this structure disciplines how the shocks are spatially propagated. Our emphasis in part on the input-output structure in the propagation of shocks after the Tohoku earthquake is motivated by the fact that much of the immediate impact of the Tohoku earthquake on other regions was driven by the decline in intermediate inputs produced in Tohoku.

\footnotetext{
${ }^{1}$ It is important, however, to keep the magnitude of the impact of the Tohoku earthquake in perspective. In fact, the negative impact of the global financial crisis in late 2008 on overall Japanese GDP was far larger than the negative impact of the Tohoku earthquake. Moreover, how the 2008 global financial crisis caused the Japanese recession at that time is vastly different from how the Tohoku earthquake caused the latest Japanese recession.

While the recession after the 2008 financial crisis was caused by a decline in Japanese investment and an exogenous fall in exports, owing to a collapse in foreign demand, the recession post-earthquake was related to the inability of Japan to produce inputs to production, such as intermediate products and energy, which led to a drawdown in inventories, a decline in the ability to supply exports, and the increased imports of raw materials.

${ }^{2}$ Let $\mathrm{GDP}=\mathrm{C}+\mathrm{I}$. Then in an accounting sense, the contribution of variable $\mathrm{C}$ to the growth in GDP is approximately $(C / G D P) * \Delta C / C$.

${ }^{3}$ During this longer period, net exports declined because of the fall in total exports and the increase in total imports. The decline in total exports contributed to dragging down GDP growth by 0.6 percent and the rise in total imports contributed to dragging down GDP growth by 1.2 percent. Much of the increase in imports was driven by the increase in natural gas and other fossil fuel imports. Energy imports increased, since Japan was faced with an energy shortage. The energy shortage was caused by a shutdown of almost all of the country's nuclear power plants, which normally provides 30 percent of Japan's total energy.
} 
However, we also examine other structures linking regions such as technological spillovers. The shocks to Tohoku are propagated spatially to other regions. The other regions in turn impact other regions with a delay. We also allow these lagged effects to echo back to Tohoku.

The literature examining the importance of the propagation of regional shocks has followed two main approaches. The first strand is rooted in more structural calibrated multi-regional models such as Caliendo et al. (2014) that explicitly take into account inter-regional linkages across sectors. This paper is in the second strand of the literature (Forni et al. (2000)) that relies on time-series methods coupled with broad identifying restrictions among regional linkages to assess the magnitude and propagation of regional shocks in the aggregate economy. The advantage of our approach is that it is flexible and allows for various types of regional linkages or economic distance measures among regions. For example, one region may not be buying much from another region, but may be strongly affected by a decline in industrial production in another region if their technologies are similar. As another example, the output of a region neighboring Tohoku may fall, not because the supply of industrial products from Tohoku fell, but because the demand from Tohoku declined. Our flexible approach allows us the handle these varying forms of regional linkages.

This is not the first paper to trace out the effects of the earthquakes and other natural disasters on Japanese output and industrial production. Tokui and Miyagawa (2014) examine how the distribution of economic activity within Japan are impacted by natural disasters. Hosono et al. (2013) examine how shocks arising from earthquakes, when interacted with financing constraints, can lower firm-level industrial production.

Perhaps the paper most related to this work is Carvalho et al. (2014). The authors use firm-level data to try to quantify the impact of supply shocks emanating from the Tohoku earthquake. They focus on existing firms in the earthquake affected areas and find that sales growth of linked firms outside the area exhibit negative and significant effects for both upstream and downstream firms. While their data is much more detailed than ours (our data are regional, and their data are firm-level), the frequency of our data (monthly) is higher than their frequency (annual). As we will see below, much of the propagation of the shocks occur at a frequency much below the annual; in our impulse response functions, the maximal negative of the earthquake shock occurs nationwide in about six months.

\section{The Impact of the 2011 Tohoku Earthquake on Aggregate and Regional Industrial Produc- tion}

GDP includes a sizable component of non-manufacturing production, including the production of services. To better isolate the impact of the disruption of the production of parts in Tohoku on Japanese manufacturing production, for 
the remainder of the paper, we focus on the measure of industrial production, which mainly captures manufacturing production. Figure 1 depicts the pattern in industrial production from the third quarter of 2008 to the third quarter of 2012. We can observe that disruptions owing from the Lehman crisis sharply lowered Japanese aggregate industrial production in the first quarter of 2009. Compared to the decline in production from the Lehman crisis, the decline in production from the earthquake was far milder.

This aggregate pattern, however, masks the wide regional disparities in the impact of the earthquake. Not surprisingly, the decline in production in Tohoku was far larger during the earthquake than during the financial crisis. The impact of the earthquake was much more regionally concentrated than the impact of the financial crisis.

In Figure 2, we show a map when the 47 prefectures are aggregated into 8 regions. We aggregate the prefectures up to this level, since the input-output tables that we use extensively below are only available at this regional breakdown. With this aggregation, Tohoku now includes Aomori, Akita, and Yamagata, in addition to the three heavily impacted prefectures of Iwate, Miyagi, and Fukushima. The Kanto region includes Japan's largest cities of Tokyo and Yokohama (Kanagawa); and the Chubu region includes the important heavy manufacturing prefectures of Aichi and Shizuoka. In this aggregation, since Chubu also includes the Hokuriku area, Chubu also turns out to be adjacent to Tohoku.

Figures 3 plot the monthly regional industrial production indices (seasonally adjusted) from 1998 to 2012 for the eight regions. The regional industrial production data used here and in the econometric analysis later are obtained from the individual websites of the regional Ministry of Economy, Trade, and Industry offices. Compared to February 2011, industrial production in Tohoku fell by 35 percent in March 2011. This decline in industrial production was much steeper than the post-financial crisis decline of 28.6 percent (between December 2008 to February 2009) in Tohoku.

While the decline was not as steep as during the financial crisis, production declined sharply post-earthquake in Kanto and Chubu. In March 2011, industrial production fell by 20 percent in Kanto and 25 percent in Chubu. The Kanto prefectures of Chiba, Saitama, Ibaragi, Tochigi, and Tokyo were directly impacted by the earthquake, but not the tsunami, so the direct damage to their capital stock was minimal. However, the Kanto region has many factories using inputs produced in the Tohoku region, so production was halted in many of the factories. Likewise, the Chubu region is Japan's industrial heartland, and many of the factories located there such as the automobile factories used inputs made in Tohoku.

Despite its geographic proximity to Tohoku, Hokkaido was spared of much of the impact of the earthquake. Kyushu, Shikoku, Kinki, and Chugoku are all located far from Tohoku. While Chugoku and Shikoku's industrial production declined after the earthquake, Kyushu's industrial production, while declining slightly after the earthquake has bounced back strongly. It is said that Kyushu produces many products that are substitutes to Tohoku's, so that Kyushu was in 
fact a beneficiary of the damage to Tohoku's production facilities. Surprisingly, Kinki, while including the industrial cities of Osaka and Kobe, was spared of the direct effects from the supply disruption of the intermediate parts produced in Tohoku.

\section{Indices of Interactions Among Japanese Re- gions}

As discussed above, the earthquake to Tohoku affected different regions in different ways. Some regions like Kanto and Chubu experienced a sharp fall in industrial production, while industrial production in Kinki, Chugoku, and other Southern regions barely budged. We have argued that the different propagation mechanisms in industrial production may be related to how different regions used the inputs produced in Tohoku or were substitutes to the inputs produced in Tohoku.

In this Section, using input-output matrices that include 17 industries in our 8 regions, we show how the different regions in Japan are "interrelated." We consider five measures of "interrelatedness." The 17 industries and 8 regions are depicted in Table 1. The measures of "interrelatedness" are: 1) how two regions are "similar" (Conley and Dupor (2003)); 2) how much one region buys from another region ("buying" matrix); 3) how much one region sells to another region; ("selling" matrix) 4) how much regions buy from each other ("mutual buying" matrix); and 5) the geographical adjacency of two regions.

\section{1 "Interrelatedness" or Economic Distance Measures}

We use the Japanese regional input-output matrices for 2005 compiled by RIETI, in which there are $N=8$ regions. The raw input-output matrices includes rows (suppliers of commodities) and columns (purchasers of commodities) that do not correspond to any industries. On the column side, besides intermediate users of commodities such as manufacturing, mining, and construction, the input-output table contains columns for other components of gross domestic product: consumption, investment, change in business inventories, and government purchases. On the row side, the input-output table contains rows for compensation to nonindustries such as wages and taxes. We address these components of the regional input-output table by: (a) removing all the final-use columns of the input-output table; and (b) dropping all additional rows of the table. Finally, the original matrix has 29 industries, but we drop "public administration", "medical services", "business services", "personal services", and "others", to arrive at $M=17$ industries, which are primarily in manufacturing.

\subsubsection{Notation}

$\Gamma$ is the input-output matrix of dimension $N \times M$ by $N \times M$. A typical $(s, b)$-th element of $\Gamma$ is $\Gamma(s, b)$, which is the total value of transactions between $s$ 's supply 
and $b$ 's purchase. In other words, the $s$-th row of $\Gamma$ corresponds to the value of sales of $s$, and the $b$-th column of $\Gamma$ corresponds to the value of purchases of $b$.

For $i, j=1, \cdots, N$ and $m, n=1, \cdots, M$, denote $\Gamma\left(i_{(m)}, j_{(n)}\right)$ as the total value of sales from region- $i$ 's industry- $m$ to region- $j$ 's industry- $n$.

\subsection{2 "Similarity" Regional Matrix}

This economic distance measure holds that two regions are close if they buy goods from similar industries (Conley and Dupor (2003)). We use the argument that regions with similar input requirements are likely to have similar technology; so that the same shock to a given region is likely to affect the output of another "similar" region, through technological spillovers.

Steps to compute the "similarity" matrix.

- calculate $B_{m}$

$$
B_{m}(i, j)=\frac{\Gamma\left(i_{(m)}, j_{(m)}\right)}{\sum_{k} \Gamma\left(k_{(m)}, j_{(m)}\right)}
$$

- calculate $B$

$$
B(i, j)=\sum_{m} B_{m}(i, j)
$$

- calculate $D^{b}$

$$
D^{b}(i, j)=\left\{\sum_{k}[B(k, i)-B(k, j)]^{2}\right\}^{1 / 2}
$$

for $i, j=1, \ldots N$.

This matrix is depicted in Table 2(a). According to this matrix, prefectures most related to Tohoku (in order) are: Kanto, Hokkaido, Kinki, Shikoku, Chubu, Chugoku, and Kyushu.

\subsubsection{Buying Regional Matrix}

Our second measure of "interrelatedness" measures how much one region is buying from another region.

$\mathcal{X}$ with $(i, j)$-the element

$$
\mathcal{X}(i, j)=\frac{\sum_{m, n} \Gamma\left(i_{(m)}, j_{(n)}\right)}{\sum_{k, m, n} \Gamma\left(k_{(m)}, j_{(n)}\right)}
$$

The term is the weight of sales from region $i$ to region $j$ among all the regions' sales to region $j$. This matrix is depicted in Table 2(b). If the first region is buying a lot from the second region, it means that the first region has a strong "downstream" connection with the second region. According to this matrix, prefectures most related to Tohoku (in order) are: Kanto, Chubu, Kinki, Chugoku, Kyushu, Hokkaido, Shikoku. 


\subsubsection{Selling Regional Matrix}

Our third measure of "interrelatedness" measures how much one region is selling to another region.

$\mathcal{X}$ with $(i, j)$-the element

$$
\mathcal{X}(i, j)=\frac{\sum_{m, n} \Gamma\left(i_{(m)}, j_{(n)}\right)}{\sum_{l, m, n} \Gamma\left(i_{(m)}, l_{(n)}\right)}
$$

The term is the weight of purchases by region $j$ from region $i$ among all the regions' purchases from region $i$. This matrix is depicted in Table 2(c). If the first region is selling a lot to the second region, it means that the first region has a strong "upstream" connection with the second region. This type of relationship among economic units is emphasized, for example, by Acemoglu et al. (2012). According to this matrix, prefectures most related to Tohoku (in order) are: Hokkaido, Kanto, Chubu, Kinki, Shikoku, Kyushu, Chugoku.

\subsubsection{Mutual Buying Regional Matrix}

In addition, our fourth measure of "interrelatedness" measures how much two regions are buying from each other, relative to their purchases from other regions. The more the two regions are buying from each other, the more dependent or "interrelated" are the two regions.

$\mathcal{X}$ with $(i, j)$-the element

$$
\mathcal{X}(i, j)=\frac{\sum_{m, n} \Gamma\left(i_{(m)}, j_{(n)}\right)}{\sum_{k, m, n} \Gamma\left(k_{(m)}, j_{(n)}\right)}+\frac{\sum_{m, n} \Gamma\left(i_{(m)}, j_{(n)}\right)}{\sum_{l, m, n} \Gamma\left(i_{(m)}, l_{(n)}\right)}
$$

This matrix is depicted in Table 2(d). According to this matrix, prefectures most related to Tohoku (in order) are: Kanto, Chubu, Kinki, Chugoku, Kyushu, Hokkaido, Shikoku.

\subsubsection{Contiguity Matrix}

The last matrix of "interrelatedness" simply assigns a value of one if the region shares a border with another region, deeming that if they share a border, they are "similar." This matrix is depicted in Table 2(e). According to this matrix, prefectures most related to Tohoku (in order) are: Hokkaido, Kanto, Chubu, Kinki, Chugoku, Shikoku, and Kyushu.

\section{Regional Spillover Effects}

\subsection{Model of Regional Spillover Effects}

We employ the diffusion model of Holly et al. (2011) to assess the shock of Tohoku earthquake on the other regions in Japan. Holly et al. (2011) designed a method for analyzing the spatial and temporal diffusion of shocks to a dominant 
region, which was applied to evaluate the effects on UK housing prices due to shocks on the housing price to London. The method treats the house price of London as a common factor and then models the contemporaneous as well as lagged dependencies among regions conditional on London house prices.We estimate using the monthly data of industrial production for the 8 Japan regions defined in the previous section. The data ranges from January 1998 to October 2012 , so that $T=178$.

Denote $p_{i t}$ as the industrial production data of region $i$ at time $t$, for $i=$ $1, \cdots, N$ and $t=1, \cdots, T$. The diffusion model has what is called the dominant region $(i=1)$ and treats this region and the rest of the regions $(i=2, \cdots, N)$ differently by allowing for the shock on the dominant region to affect the other regions not only contemporaneously but also through lagged impacts, while allowing for no contemporaneous effects from the rest of the regions on the dominant region.

For regions $i=2, \cdots, N$,

$$
\begin{aligned}
\Delta p_{i t} & =\phi_{i s}\left(p_{i, t-1}-\bar{p}_{i, t-1}^{s}\right)+\phi_{i 1}\left(p_{i, t-1}-p_{1, t-1}\right)+a_{i} \\
& +\sum_{l=1}^{k_{i a}} a_{i l} \Delta p_{i, t-l}+\sum_{l=1}^{k_{i b}} b_{i l} \Delta \bar{p}_{i, t-l}^{s}+\sum_{l=1}^{k_{i c}} c_{i l} \Delta p_{1, t-l}+c_{i 0} \Delta p_{1 t}+\varepsilon_{i t}(1)
\end{aligned}
$$

For region $i=1, \phi_{11}$ and $c_{10}$ are set to be 0 in the above equation (1), where

$$
\bar{p}_{i t}^{s}=\sum_{j=1}^{N} S_{i j} p_{j t}, \text { with } \sum_{j=1}^{N} S_{i j}=1
$$

That is, in region 1 , the dominant region is not affected by the contemporaneous shocks in any other region.In the estimation of the model above, we take Kanto (Tokyo) as the dominant region. Tokyo's industrial production is assumed to be only affected by its own lagged industrial production and the lagged effects of its neighbor's industrial production. The industrial production of other regions is assumed to be affected by not only the lagged effects of Tokyo and the remaining regions, but also the contemporary effects of the shocks to Tokyo. The reason why we take Tokyo as the common factor is that on average during the period of the model's estimation, 1998-2012, shocks to Tokyo were clearly the most important for the whole of Japan, given that Tokyo's GDP is about 30 percent of Japan's GDP 4 .

$S_{i j} \geq 0$ is the $(i, j)$-th element of weighted spatial matrix $S$, which measures the spatial connection between region $i$ and region $j$. Note that the influence of the other regions with exception of Kanto is entirely captured by $\bar{p}_{i t}^{s}$, which

\footnotetext{
${ }^{4}$ The "common factor" approach to estimation treats the contemporaneous correlations among the regions by assuming that all the regions are affected by the common economy-wide shock, but with differing intensities. In our model, we treat the industrial production of the dominant region, Kanto, as the common factor. By doing so, we can consistently estimate error correction models conditional on the common factor, Kanto's industrial production, independently, region by region, and ignore the correlations among the error terms across the regions (Pesaran (2006)), $\varepsilon_{i t}$.
} 
weights the industrial productions of the other regions by the spatial weighting matrix, $S_{i j}$. Thus, $\bar{p}_{i t}^{s}$ through the spatial weighting matrix captures how the shocks from say Tohoku, propagates to Kyushu. The structure of the spatial weighting matrix laid out in the previous section captures how two regions are interrelated.

As pointed out by Holly et al. (2011), the error correcting specification of equation (1) is a parsimonious representation of pair-wise cointegration of the data across regions. In addition, weak exogeneity of $\Delta p_{1 t}$ in equation (1) can be tested by the procedure of Wu (1973).

\subsection{Spatio-temporal Impulse Response Functions}

We can use the estimates from the model above to examine impulse responses both over time and space. The persistence profile of shocks to the system over time and across regions can be evaluated using generalized impulse response function (GIRF), initially advanced by Pesaran and Shin (1998).

For horizons $h=0,1, \cdots$, the impulse response of a unit (i.e. a standard deviation) shock on the dominant region is computed as

$$
\begin{aligned}
g_{1}(h) & =E\left(\boldsymbol{p}_{t+h} \mid \varepsilon_{1 t}=\sqrt{\sigma_{11}}, \mathcal{F}_{t-1}\right)-E\left(\boldsymbol{p}_{t+h} \mid \mathcal{F}_{t-1}\right) \\
& =\sqrt{\sigma_{11}} \boldsymbol{\Psi}_{h} \boldsymbol{R}_{1}
\end{aligned}
$$

where $\boldsymbol{p}_{t}=\left(p_{1 t}, \cdots, p_{N t}\right)^{\prime}$ is the vector of industrial production data at time $t, \mathcal{F}_{t}$ is the filtration of information up to time $t, \sigma_{11}=\operatorname{var}\left(\varepsilon_{1 t}\right)$, and $\boldsymbol{e}_{1}=(1,0, \cdots, 0)^{\prime}$. By stacking the $N$ regressions in (1), Holly et al. (2011) derived that ${ }^{5}$

$$
\Delta \boldsymbol{p}_{t}=\boldsymbol{a}+\boldsymbol{H} \boldsymbol{p}_{t-1}+\sum_{l=1}^{k}\left(\boldsymbol{A}_{l}+\boldsymbol{G}_{l}\right) \Delta \boldsymbol{p}_{t-l}+\sum_{l=0}^{k} \boldsymbol{C}_{l} \Delta \boldsymbol{p}_{t-l}+\varepsilon_{t}
$$

where $\boldsymbol{a}, \boldsymbol{H}, \boldsymbol{A}_{l}, \boldsymbol{G}_{l}$, and $\boldsymbol{C}_{l}$ are matrices of model parameters. It can be solved from the above expression to get

$$
\Delta \boldsymbol{p}_{t}=\boldsymbol{\mu}+\boldsymbol{\Pi} \boldsymbol{p}_{t-1}+\sum_{l=1}^{k} \gamma_{l} \Delta \boldsymbol{p}_{t-l}+\boldsymbol{R} \boldsymbol{\varepsilon}_{t}
$$

where $k=\max _{i}\left\{k_{i a}, k_{i b}, k_{i c}\right\}, \boldsymbol{\mu}=\boldsymbol{R a}$ with $\boldsymbol{R}=\left(\boldsymbol{I}_{N}-\boldsymbol{C}_{0}\right)^{-1}, \boldsymbol{\Pi}=\boldsymbol{R} \boldsymbol{H}$, $\gamma_{l}=\boldsymbol{R}\left(\boldsymbol{A}_{l}+\boldsymbol{G}_{l}+\boldsymbol{C}_{l}\right)$.

In a VAR form, this implies that

$$
\boldsymbol{p}_{t}=\boldsymbol{\mu}+\sum_{l=1}^{k+1} \boldsymbol{\Phi}_{l} \boldsymbol{p}_{t-l}+\boldsymbol{R} \varepsilon_{t}
$$

where $\boldsymbol{\Phi}_{1}=\boldsymbol{I}_{N}+\boldsymbol{\Pi}+\gamma_{1}, \boldsymbol{\Phi}_{l}=\gamma_{l}-\gamma_{l-1}$ for $l=2, \cdots, k$ and $\boldsymbol{\Phi}_{k+1}=-\gamma_{k}$.

\footnotetext{
${ }^{5}$ See Holly et al. (2011) for detailed derivations of the generalized impulse response function in the spatial temporal model.
} 
Then for $h=0,1, \cdots, \mathbf{\Psi}_{h}$ in equation (2) is defined as

$$
\boldsymbol{\Psi}_{h}=\sum_{l=1}^{k+1} \Phi_{l} \boldsymbol{\Psi}_{h-l}
$$

\section{Empirical Results}

\subsection{Regions and their Connection}

Kanto (Tokyo) is set as the dominant region in model (1) to account for both of its contemporaneous and intertemporal impacts. Given the common factor structure, we follow Holly et al. (2011) to estimate model (1) equation by equation using OLS.

Also, we construct the weighted spatial matrices based on our five measures of regional "interrelatedness" or economic distance.

\subsection{Estimation Results}

The estimation results are depicted in Table 3. Table 3(a) reports the results based on the row standardized "Similarity" matrix, Table 3(b) reports the results based on the row standardized "Buying" matrix, Table 3(c) reports the results based on the row standardized "Selling" matrix, Table 3(d) reports the results based on the row standardized "Mutual Buying" matrix, and Table 3(e) reports the results based on the row standardized "Contiguity" matrix. We can see that results from Table 3(a)-(e) are similar in the following ways.

"Own lag" is the estimated $\sum_{l=1}^{k_{i a}} a_{i l}$. A positive "own lag" effect implies that the series continues to drift in the same direction as the last period, exhibiting either an upward trend or a downward trend. A negative "own lag" effect implies that the series adjusts to last period's increase by a decrease in the current period, exhibiting a property like mean reverting. Estimation based on the "Similarity" matrix identifies the own lag effects of Tohoku, Hokkaido, Chubu, Kinki, Chugoku, and Shikoku to be significant. Estimations based on the "Mutual Buying" matrix and the "Contiguity" matrix identify the same set of significant own lag effects, ie. own lag effects are only found to be insignificant for Kanto and Kyushu.

"Neighbour lag" estimates the dynamic spillover effects $\sum_{l=1}^{k_{i b}} b_{i l}$. A positive "neighbour lag" effect implies that the series moves in the same direction as the weighted average of its neighbour in the last period. A negative "neighbour lag" effect implies the series moves in the opposite direction. Both the estimation based on the "Similarity" matrix and the estimation based on the "Mutual Buying" matrix identify the same set of significant neighbour lag effects in Hokkaido, Kinki, Chugoku, Shikoku, and Kyushu. Estimation based on the "Contiguity" matrix identifies significant neighbour lag effects in Chubu, Kinki, Chugoku, Shikoku, and Kyushu. Finally, based on all three "interrelatedness" measures, the estimated neighbour lag effects on all the regions are positive, 
except for the neighbour lag effect on Tohoku and the neighbour lag effect of Kanto when the Contiguity matrix is used as the "interrelatedness" or economic distance measure. Thus, for all five measures of "interrelatedness" or economic distance, industrial production shocks are positively correlated among regions, with the exception of Tohoku or Hokkaido.

With regards to the magnitudes of the "neighbor" lags estimates, the "selling" matrix has the smallest coefficients, followed by the "mutual buying matrix." The "selling" matrix captures how much the neighbors are buying from the region in question. The "selling" matrix captures how much the industrial production of the upstream firm is affected by demand from the downstream firm.

"Kanto lag" is the estimated lagged effect of Kanto. A positive "Kanto lag" effect implies that the series moved in the same direction as Kanto did in the last period. Based on all the connectedness measures, the estimated "Kanto lag" effects are found to be significantly positive for Tohoku. Significantly positive "Kanto lag" effects are also observed for Chubu when using the "Similarity matrix" and "Mutual buying matrix" and for Hokkaido when using the "Contiguity matrix".

"Kanto current" is the estimated contemporaneous effect of Kanto, $c_{i 0}$. A positive "Kanto current" effect implies that the series simultaneously moves in the same direction as Kanto. Based on all the connectedness measures, the estimated "Kanto current" effects are similar, and all of them are significantly positive.

EC1 is estimated $\phi_{i 1}$, which is referred to as the error correction term of $\left(p_{i, t-1}-p_{1, t-1}\right)$, the deviations of region $i$ from Kanto. The estimated EC1 are similar based on the three connectedness measures, which give a significantly negative EC1 for Chugoku; the Similarity matrix additionally identifies that Tohoku also has a significantly negative EC1. EC2 is the estimated $\phi_{i s}$, the error correction term of $\left(p_{i, t-1}-\bar{p}_{i, t-1}^{s}\right)$, the deviation of region $i$ from its neighbours. The estimated EC2 based on the three "interrelatedness measures" identify Chugoku and Shikoku to have significantly negative EC2; the "Mutual Buying matrix" and the "Contiguity Matrix" both identify Tohoku to have a significantly negative EC2.

WH-stat is the Wu-Hausman test statistics (Wu (1973)) testing the null hypothesis that production changes in the dominant region Kanto are exogenous to production changes in the other regions. The results show that most of the regressions passed the $\mathrm{Wu}$-Hausman test, except for the regression of Hokkaido based on the "Contiguity" matrix.

$k_{i a}, k_{i b}$, and $k_{i c}$ are all selected by the Schwarz Bayesian criterion (SBC). Based on all three "interrelatedness" measures, SBC selected $k_{i a}$ to be equal to 1 and $k_{i b}$ to be equal to 1 or 2 . SBC selected the lag orders $k_{i c}=0$, producing the estimated "Kanto lag" effects, $\sum_{l=1}^{k_{i c}} c_{i l}$, to be 0 for Kinki, Chugoku, Shikoku, and Kyushu. 


\subsection{Impulse Response Functions}

Figures 4 to Figure 8 plot the estimated generalized impulse response functions (GIRF) caused by a 1 unit (i.e. 1 standard deviation) positive shock to Tohoku's industrial production.

The persistence profile of Tohoku shows that it takes about 2 years for Tohoku to absorb $1 / 2$ of a positive unit of shock to its monthly industrial production level. Interestingly, the impulse responses are quite similar across the "interrelatedness" measures. For example, across all five measures of economic distance, the peak effect occurs in about 6 months, after which the effects from the Tohoku industrial production shock declines. Across all five "interrelatedness" measures, the largest impact of the Tohoku shock occurs in order, in Chubu, Chugoku, Kyushu, Kinki, Kanto, and Shikoku. While the ordering of the impacts of the Tohoku shock do not differ by the "interrelatedness" measures, the magnitudes of the effects differ somewhat. For example, the largest effect of the Tohoku shock on Chubu is highest when we use the economic distance measure of "buying" or "mutual buying". This suggests that Tohoku's relationship with Chubu can be characterized as "downstream". That is, Tohoku buys a lot of intermediate inputs from Chubu.

This invariance of the regional propagation of shocks to the five economic distance measures can also be seen in Figure 9. For selected time periods $h=0,3,5,10,20,50$, Figure 9 depicts the Impulse Response functions across regions and over time. The regions are ordered on the horizontal axis from left to right according to their economic distance (according to each of the five "interrelatedness" matrices) to Tohoku. For example, in Figure 9(a), according to the "similarity" matrix, the ordered horizontal axis shows that the "closest" region to Tohoku is Kanto, followed by Hokkaido, Kinki, Shikoku, Chubu, Chugoku, and Kyushu.

If economic distance - according to our five definitions - results in higher spillovers, then we should see a declining pattern in the graphs. As the regions become further from Tohoku, the impact of the Tohoku shock should dissipate. In general we see no such pattern in the graphs. As seen above, Chubu industrial production always has the largest response to a Tohoku industrial production shock.

\subsection{Quantification}

Here we quantify the aggregate, nationwide effects of the Tohoku earthquake and tsunami. During our sample period, a one standard deviation shock to Tohoku industrial production (IP) was about a 11 percent decline. As mentioned, during the month of March 2011, Tohoku IP fell by 35 percent, which is about a 3 standard deviation decline in Tohoku IP.

As seen above, the calculated impulse responses are generally invariant to the five "interrelatedness" or economic distance measures. Let us then without loss of generality, take the time series patterns and magnitudes from the impulse response functions from the "mutual buying" matrix. 
By taking the weighted sum of the eight region specific multipliers (from the impulse responses), we can see that a one-standard deviation negative shock to Tohoku IP will lower nationwide IP by 2.3 percent, 4 percent, and 3.2 percent in one, six, and twenty months. (The weights are from the region's share of aggregate IP. Kanto, for example, comprises about 39 percent of aggregate IP.) Multiplying these by 3 (the earthquake shock to Tohoku in standard deviations), the aggregate impact of the Tohoku earthquake are 6 percent, 12 percent, and 9.6 percent in one, six, and twenty months.

\section{Conclusion}

In this paper, we traced out how a decline in industrial production in one region can be propagated throughout Japan. We examine how a shock to industrial production in Tohoku - owing to the earthquake - can be propagated throughout Japan. In our econometric model, regions and industries within regions are linked by specific measures of economic distance and these measures of economic distance disciplines how the shocks are spatially propagated.

In general, while we definitely find effects on industrial production from the Tohoku earthquake, the regional effects do not seem to depend much on our five definitions of economic distance, although we observe significant heterogeneity in how different prefectures were affected by the spillovers from the Tohoku earthquake. For all economic distance measures, the effect of the Tohoku earthquake and tsunami are largest on the Chubu region.

\section{References}

Acemoglu, D., Carvalho, V. M., Ozdaglar, A., and Tahbaz-Salehi, A. (2012). The network origins of aggregate fluctuations. Econometrica, 80(5).

Caliendo, L., Parro, F., Rossi-Hansberg, E., and Sarte, P.-D. (2014). The impact of regional and sectoral productivity changes on the u.s. economy. NBER Working Paper 20168.

Carvalho, V. M., Nirei, M., and Saito, Y. (2014). Supply Chain Disruptions: Evidence from the Great East Japan Earthquake. Discussion papers 14035 , Research Institute of Economy, Trade and Industry (RIETI).

Conley, T. G. and Dupor, B. (2003). A spatial analysis of sectoral complementarity. Journal of Political Economy, 111(2):311-352.

Dupor, B. (1999). Aggregation and irrelevance in multi-sector models. Journal of Monetary Economics, 43(2):391 - 409.

Forni, M., Hallin, M., Lippi, M., and Reichlin, L. (2000). The generalized dynamic-factor model: Identification and estimation. The Review of Economics and Statistics, 82(4):540-554. 
Holly, S., Pesaran, M. H., and Yamagata, T. (2011). The spatial and temporal diffusion of house prices in the uk. Journal of Urban Economics, 69(1):2 - 23.

Hosono, K., Miyakawa, D., Uchino, T., Hazama, M., Ono, A., Uchida, H., and Uesugi, I. (2013). Natural disasters, damage to banks and firm investment. mimeographed.

Pesaran, H. H. and Shin, Y. (1998). Generalized impulse response analysis in linear multivariate models. Economics Letters, 58(1):17-29.

Pesaran, M. H. (2006). Estimation and inference in large heterogeneous panels with a multifactor error structure. Econometrica, 74(4):967-1012.

Tokui, J. K. K. and Miyagawa, T. (2014). Economic effects of the great japan earthquake. mimeographed, Gakushuiin University.

Wu, D.-M. (1973). Alternative tests of independence between stochastic regressors and disturbances. Econometrica, 41(4):733-50. 
Table 1: Regions and Industries

\begin{tabular}{lc}
\hline & (a) Regions \\
\hline 01 & Hokkaido \\
02 & Tohoku \\
03 & Kanto \\
04 & Chubu \\
05 & Kinki \\
06 & Chugoku \\
07 & Shikoku \\
08 & Kyushu + Okinawa \\
\hline & (b) Industries \\
\hline 020 & Mining \\
030 & Beverages and Foods \\
040 & Textile products \\
050 & Timber, wooden products and furniture \\
060 & Pulp, paper, paperboard, building paper \\
070 & Chemical products \\
080 & Petroleum and coal products \\
090 & Plastic products \\
100 & Ceramic, stone and clay products \\
110 & Iron or steel products \\
120 & Non-ferrous metal products \\
130 & Metal products \\
140 & General machinery \\
150 & Electrical machinery \\
160 & Transportation equipment \\
170 & Precision instruments \\
180 & Miscellaneous manufacturing products \\
\hline
\end{tabular}


Table 2: Distance Measures

(a) Similarity Matrix

\begin{tabular}{|c|c|c|c|c|c|c|c|c|}
\hline & Tohoku & Hokkaido & Kanto & Chubu & Kinki & Chugoku & Shikoku & Kyushu \\
\hline Kanto & 0 & 11.366 & 12.227 & 13.034 & 12.703 & 14.064 & 12.999 & 13.905 \\
\hline Tohoku & 11.366 & 0 & 11.843 & 12.612 & 11.996 & 13.105 & 11.998 & 13.295 \\
\hline Hokkaido & 12.227 & 11.843 & 0 & 12.352 & 12.127 & 13.169 & 12.046 & 13.476 \\
\hline Chubu & 13.034 & 12.612 & 12.352 & 0 & 11.497 & 12.993 & 12.050 & 13.356 \\
\hline Kinki & 12.703 & 11.996 & 12.127 & 11.497 & 0 & 11.648 & 9.848 & 12.287 \\
\hline Chugoku & 14.064 & 13.105 & 13.169 & 12.993 & 11.648 & 0 & 10.812 & 12.414 \\
\hline Shikoku & 12.999 & 11.998 & 12.046 & 12.050 & 9.848 & 10.812 & 0 & 11.796 \\
\hline Kyushu & 13.905 & 13.295 & 13.476 & 13.356 & 12.287 & 12.414 & 11.796 & 0 \\
\hline \multicolumn{9}{|c|}{ (b) Buying Matrix } \\
\hline & Kanto & Tohoku & Hokkaido & Chubu & Kinki & Chugoku & Shikoku & Kyushu \\
\hline Kanto & 0 & 0.2400 & 0.1535 & 0.1661 & 0.1294 & 0.0831 & 0.1020 & 0.1399 \\
\hline Tohoku & 0.0395 & 0 & 0.0285 & 0.0146 & 0.0149 & 0.0101 & 0.0103 & 0.0151 \\
\hline Hokkaido & 0.0116 & 0.0137 & 0 & 0.0091 & 0.0069 & 0.0031 & 0.0051 & 0.0046 \\
\hline Chubu & 0.0908 & 0.0963 & 0.0587 & 0 & 0.1214 & 0.0657 & 0.0683 & 0.1057 \\
\hline Kinki & 0.0632 & 0.0638 & 0.0388 & 0.0856 & 0 & 0.0773 & 0.1265 & 0.0726 \\
\hline Chugoku & 0.0337 & 0.0283 & 0.0217 & 0.0422 & 0.0716 & 0 & 0.0898 & 0.0740 \\
\hline Shikoku & 0.0125 & 0.0095 & 0.0086 & 0.0110 & 0.0213 & 0.0147 & 0 & 0.0215 \\
\hline Kyushu & 0.0201 & 0.0169 & 0.0089 & 0.0187 & 0.0311 & 0.0357 & 0.0399 & 0 \\
\hline \multicolumn{9}{|c|}{ (c) Selling Matrix } \\
\hline & Kanto & Tohoku & Hokkaido & Chubu & Kinki & Chugoku & Shikoku & Kyushu \\
\hline Kanto & 0 & 0.0294 & 0.0066 & 0.0954 & 0.0521 & 0.0231 & 0.0067 & 0.0263 \\
\hline Tohoku & 0.3216 & 0 & 0.0096 & 0.0653 & 0.0468 & 0.0218 & 0.0053 & 0.0221 \\
\hline Hokkaido & 0.2271 & 0.0315 & 0 & 0.0978 & 0.0522 & 0.0161 & 0.0063 & 0.0162 \\
\hline Chubu & 0.1647 & 0.0205 & 0.0044 & 0 & 0.0850 & 0.0317 & 0.0078 & 0.0345 \\
\hline Kinki & 0.1603 & 0.0190 & 0.0041 & 0.1196 & 0 & 0.0522 & 0.0203 & 0.0332 \\
\hline Chugoku & 0.1135 & 0.0112 & 0.0030 & 0.0782 & 0.0931 & 0 & 0.0191 & 0.0449 \\
\hline Shikoku & 0.1747 & 0.0156 & 0.0050 & 0.0852 & 0.1155 & 0.0550 & 0 & 0.0542 \\
\hline Kyushu & 0.1269 & 0.0125 & 0.0023 & 0.0647 & 0.0756 & 0.0598 & 0.0159 & 0 \\
\hline \multicolumn{9}{|c|}{ (d) Mutual Buying Matrix } \\
\hline & Tohoku & Hokkaido & Kanto & Chubu & Kinki & Chugoku & Shikoku & Kyushu \\
\hline Kanto & 0 & 0.269 & 0.160 & 0.261 & 0.182 & 0.106 & 0.109 & 0.166 \\
\hline Tohoku & 0.361 & 0 & 0.038 & 0.080 & 0.062 & 0.032 & 0.016 & 0.037 \\
\hline Hokkaido & 0.239 & 0.045 & 0 & 0.107 & 0.059 & 0.019 & 0.011 & 0.021 \\
\hline Chubu & 0.256 & 0.117 & 0.063 & 0 & 0.206 & 0.097 & 0.076 & 0.140 \\
\hline Kinki & 0.224 & 0.083 & 0.043 & 0.205 & 0 & 0.130 & 0.147 & 0.106 \\
\hline Chugoku & 0.147 & 0.039 & 0.025 & 0.120 & 0.165 & 0 & 0.109 & 0.119 \\
\hline Shikoku & 0.187 & 0.025 & 0.014 & 0.096 & 0.137 & 0.070 & 0 & 0.076 \\
\hline Kyushu & 0.147 & 0.029 & 0.011 & 0.083 & 0.107 & 0.096 & 0.056 & 0 \\
\hline \multicolumn{9}{|c|}{ (e) Contiguity Matrix } \\
\hline & Tohoku & Hokkaido & Kanto & Chubu & Kinki & Chugoku & Shikoku & Kyushu \\
\hline Tohoku & 0 & 1 & 1 & 1 & 0 & 0 & 0 & 0 \\
\hline Hokkaido & 1 & 0 & 0 & 0 & 0 & 0 & 0 & 0 \\
\hline Kanto & 1 & 0 & 0 & 1 & 0 & 0 & 0 & 0 \\
\hline Chubu & 1 & 0 & 1 & 0 & 1 & 0 & 0 & 0 \\
\hline Kinki & 0 & 0 & 0 & 1 & 0 & 1 & 1 & 0 \\
\hline Chugoku & 0 & 0 & 0 & 0 & 1 & 0 & 1 & 1 \\
\hline Shikoku & 0 & 0 & 0 & 0 & 1 & 1 & 0 & 1 \\
\hline Kyushu & 0 & 0 & $0^{17}$ & 0 & 0 & 1 & 1 & 0 \\
\hline
\end{tabular}




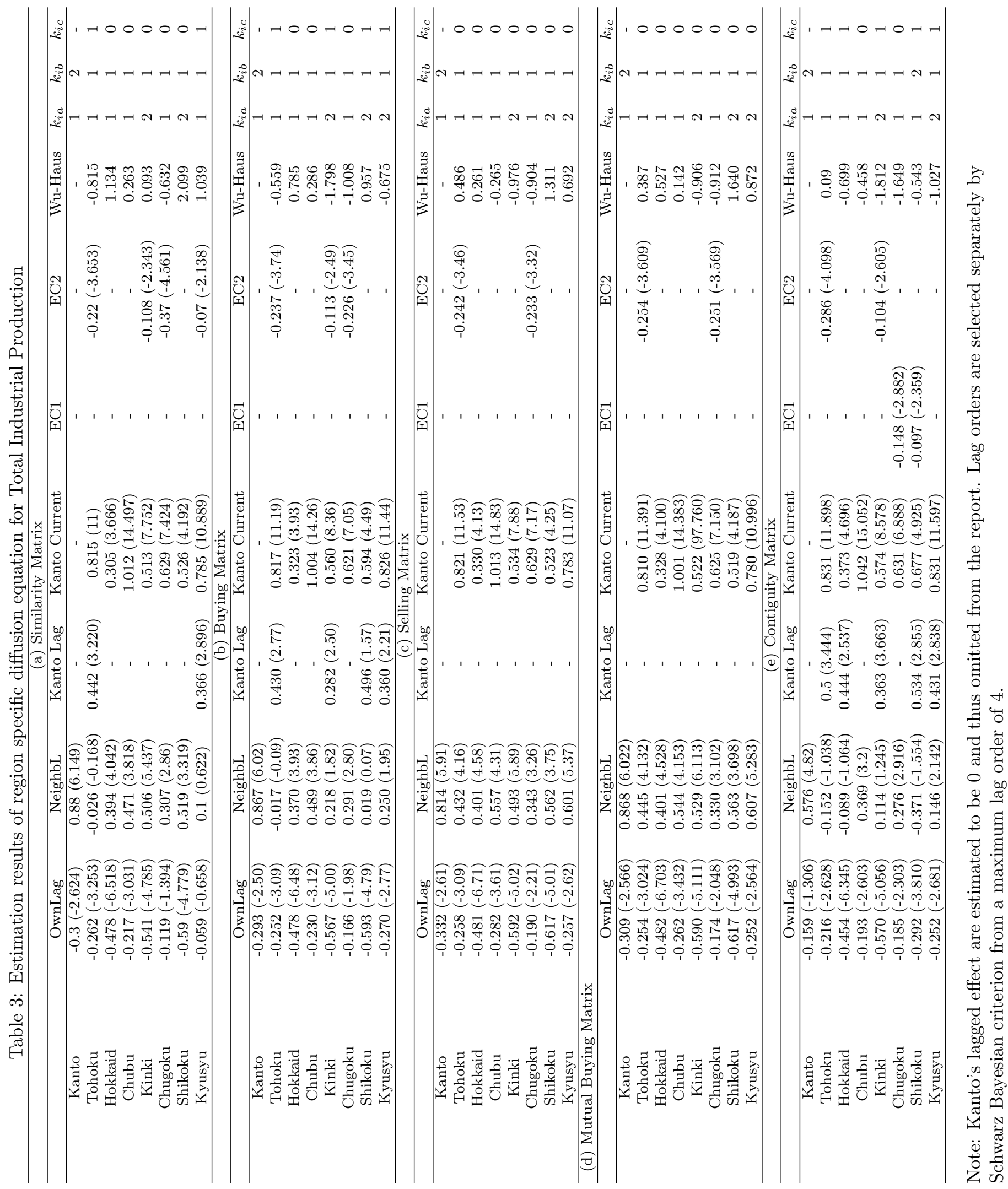




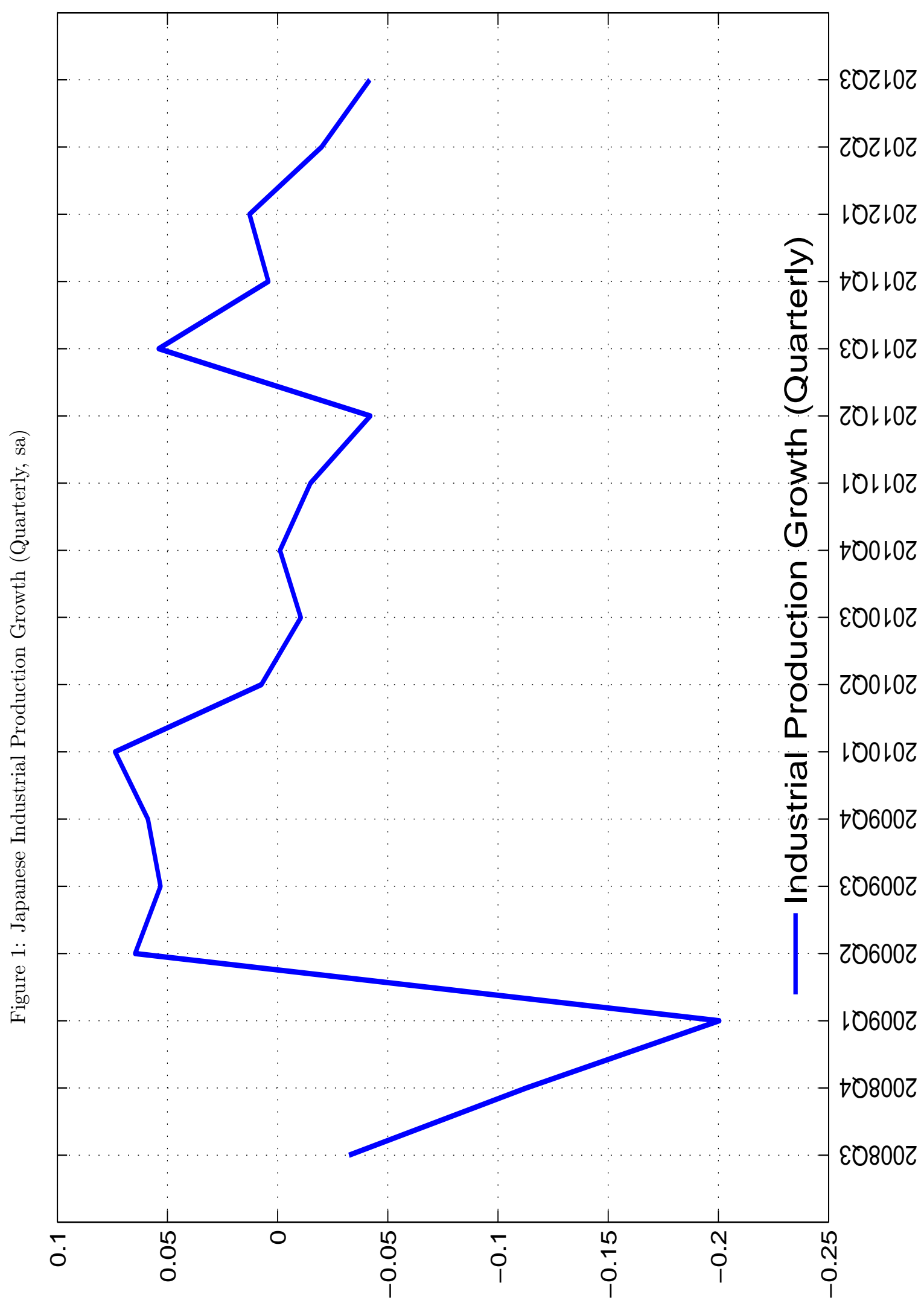


Figure 2: Japanese Regional Map

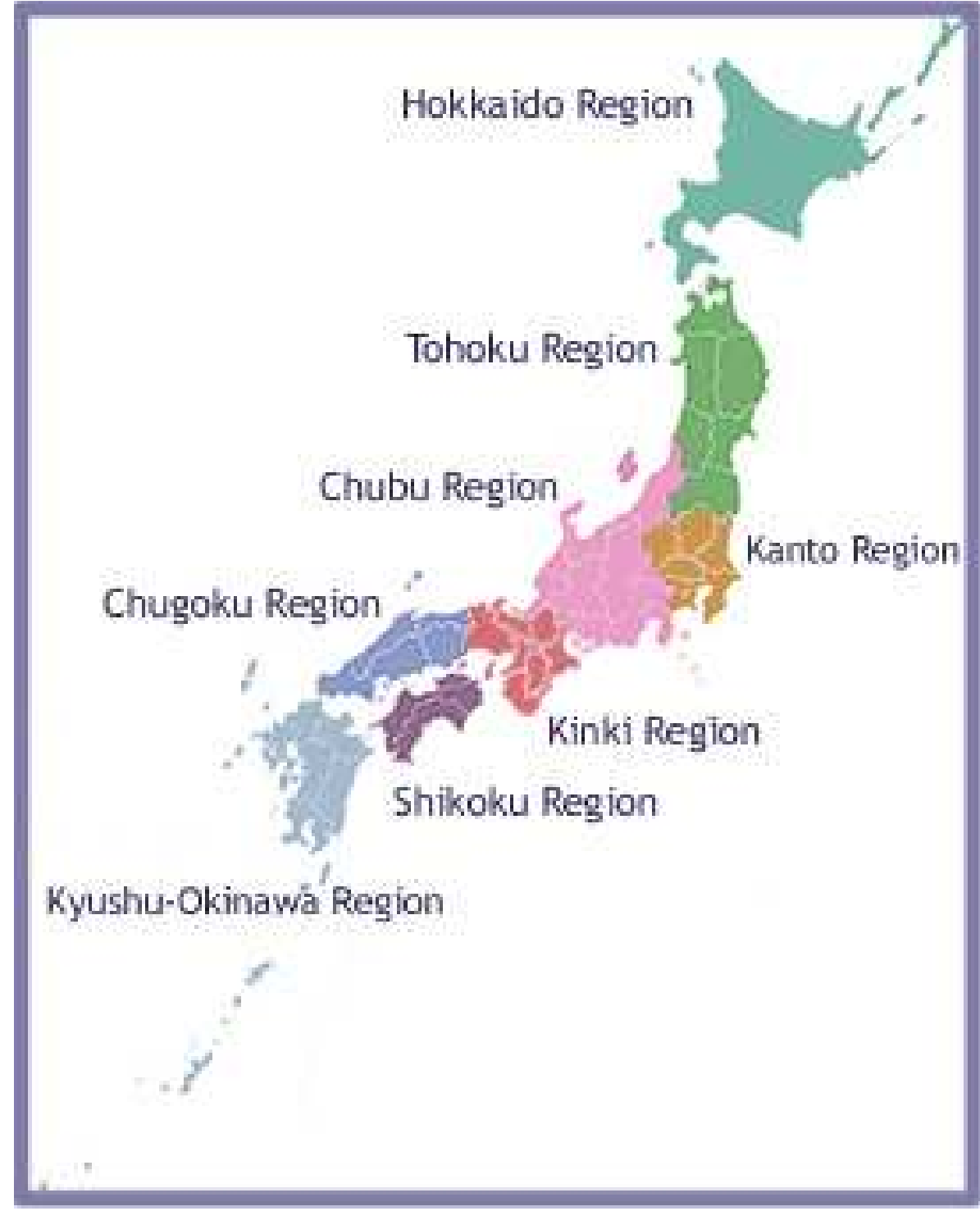



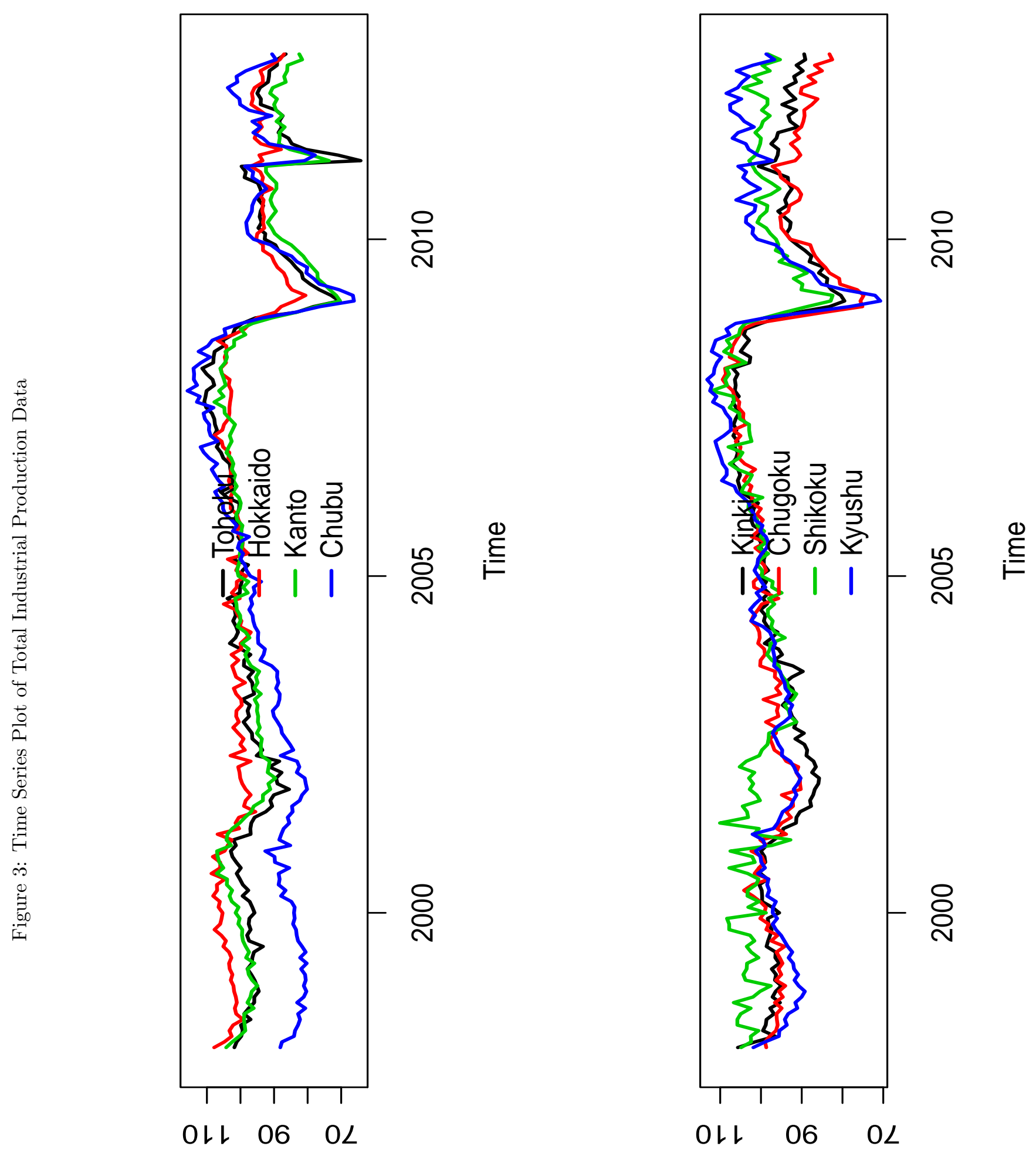
Figure 4: Shock on IP based on Similarity matrix
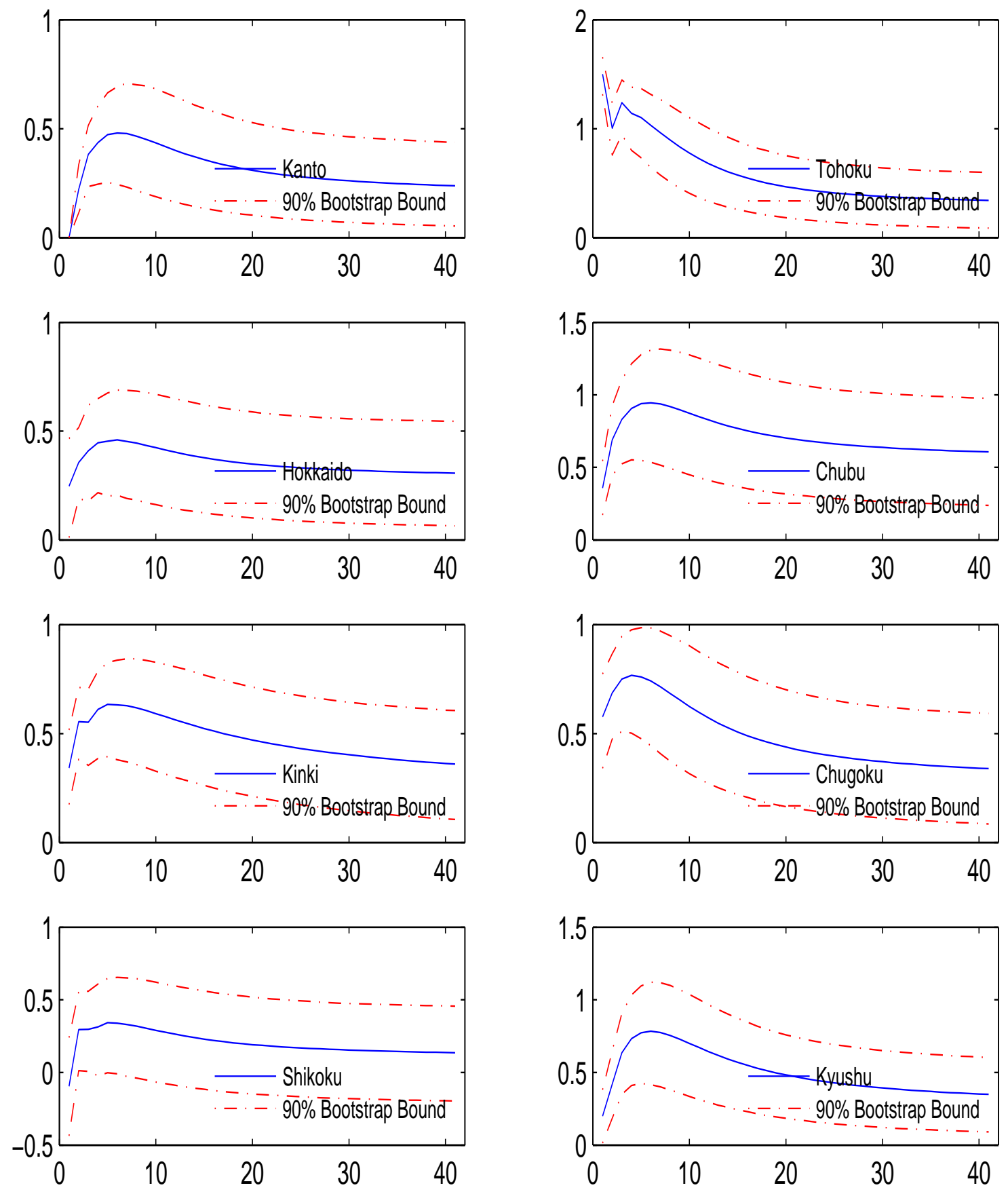
Figure 5: Shock on IP based on Buying Matrix
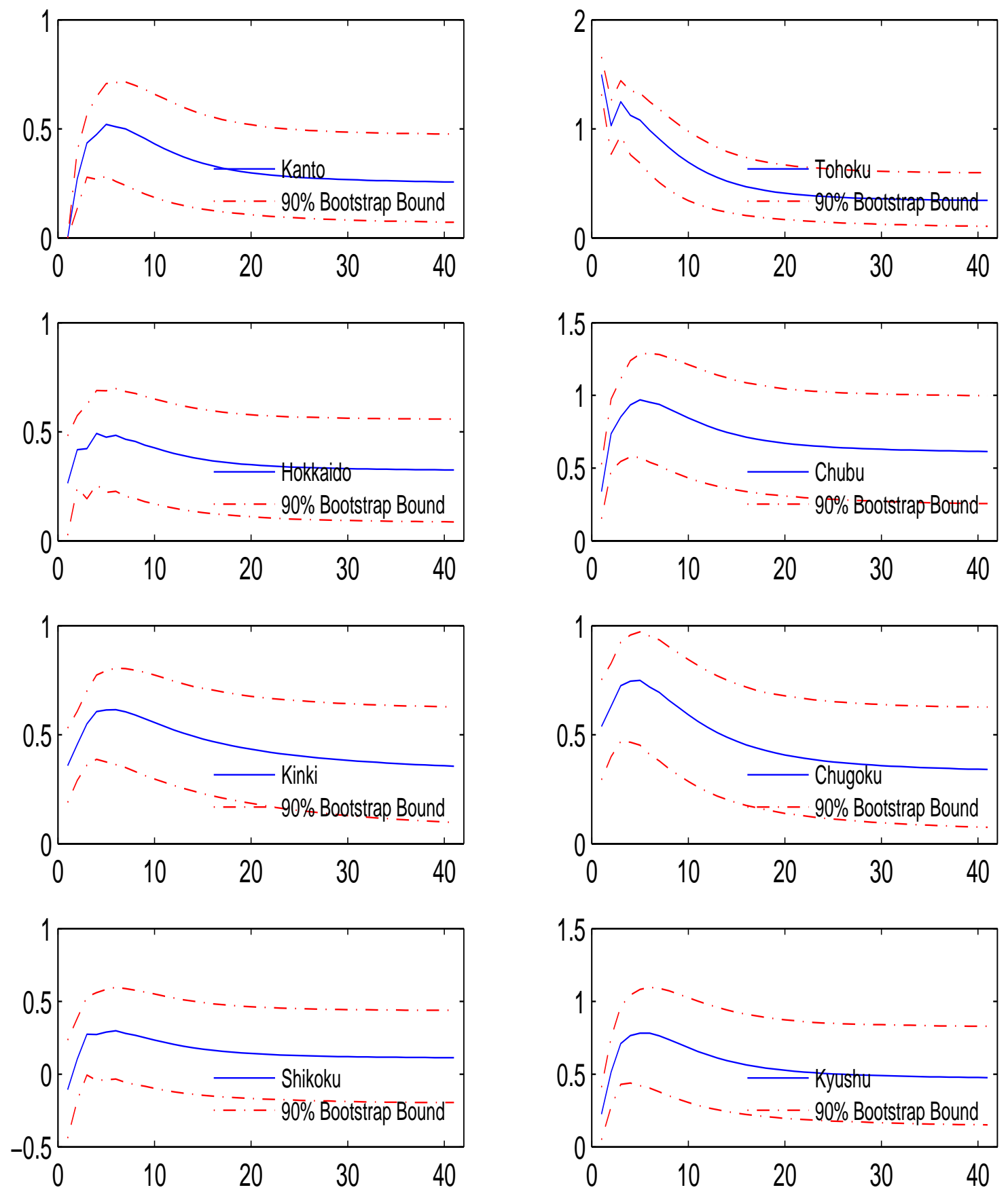
Figure 6: Shock on IP based on Selling Matrix
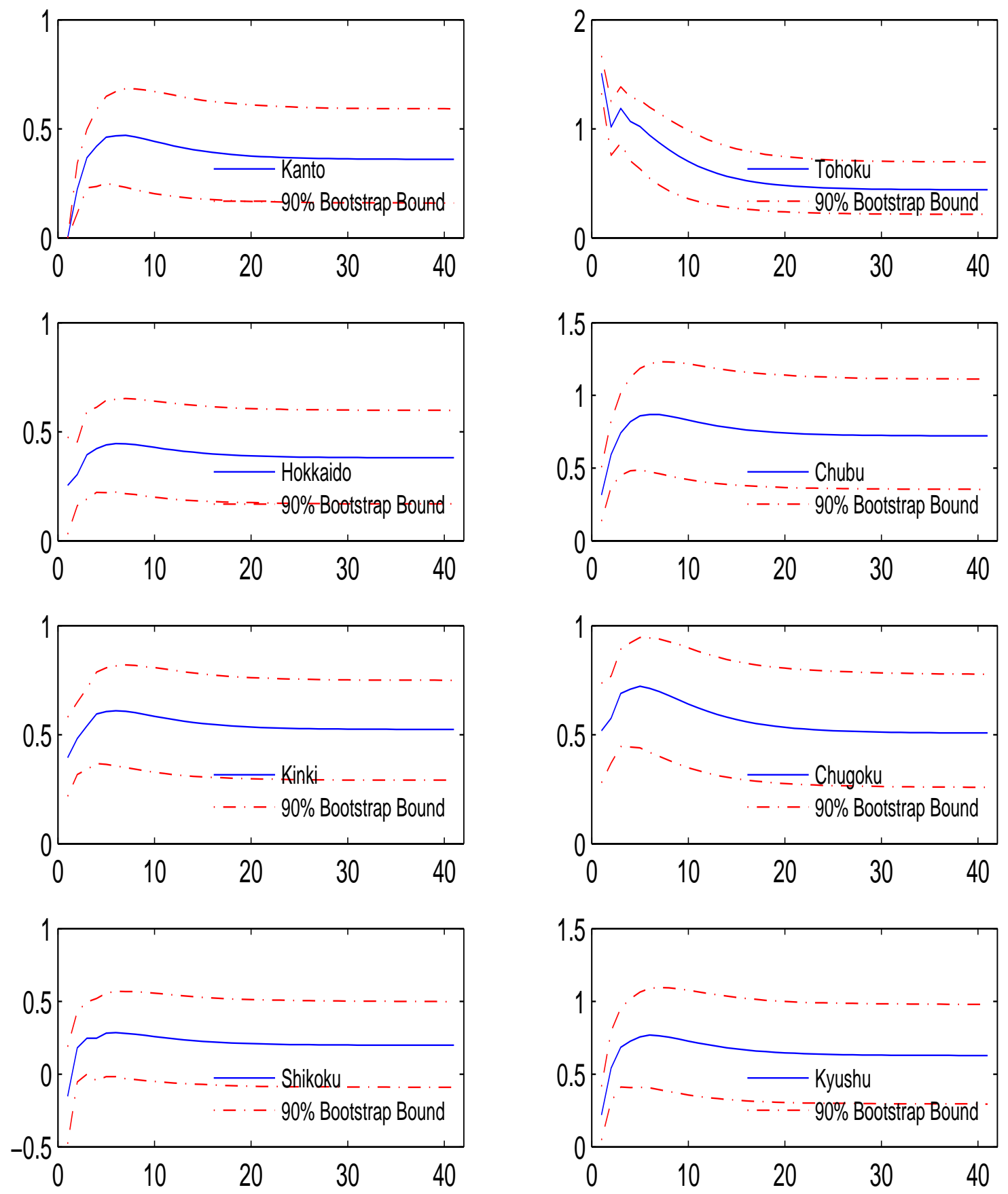
Figure 7: Shock on IP based on Mutual Buying Matrix
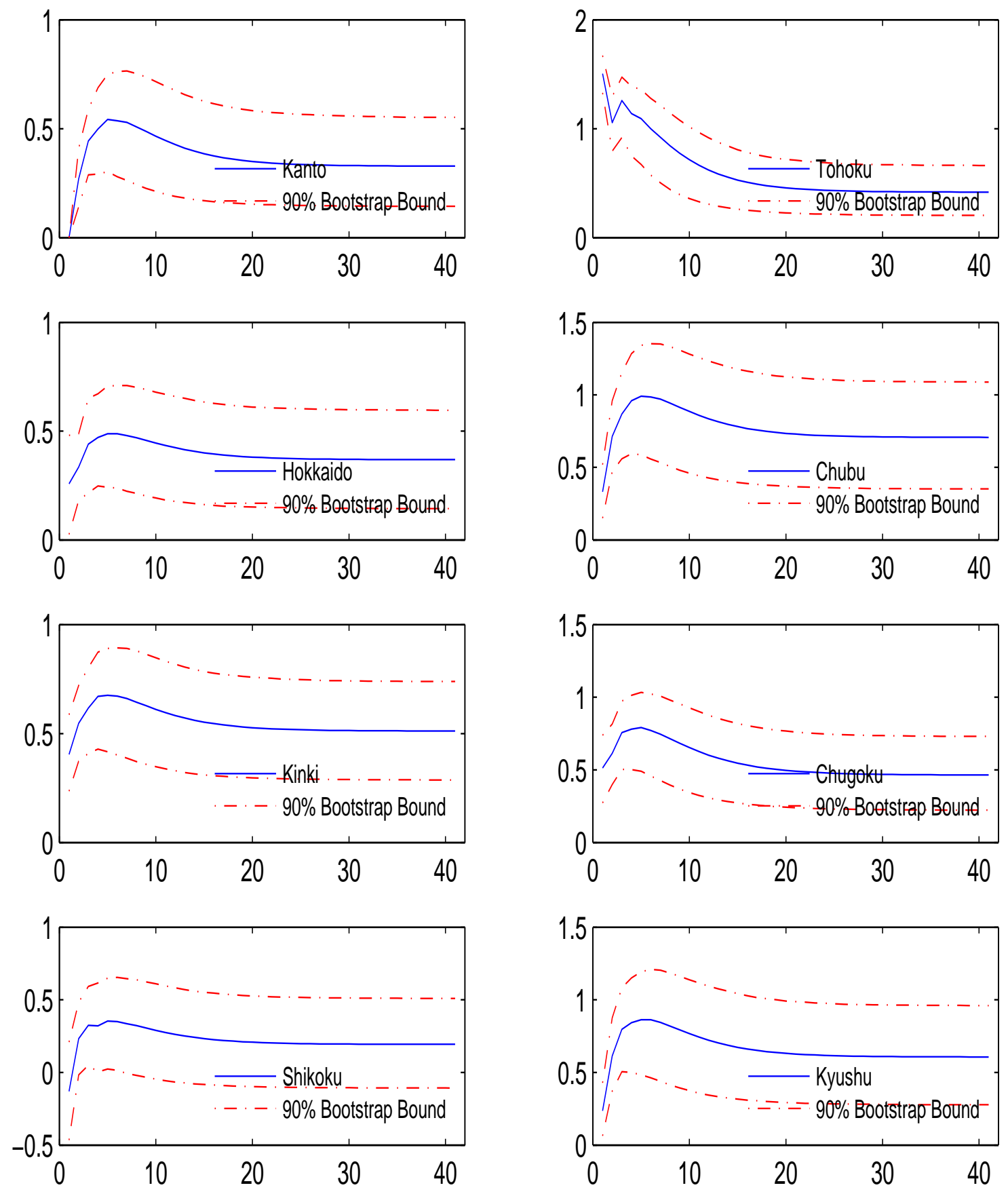
Figure 8: Shock on IP based on Contiguity Matrix
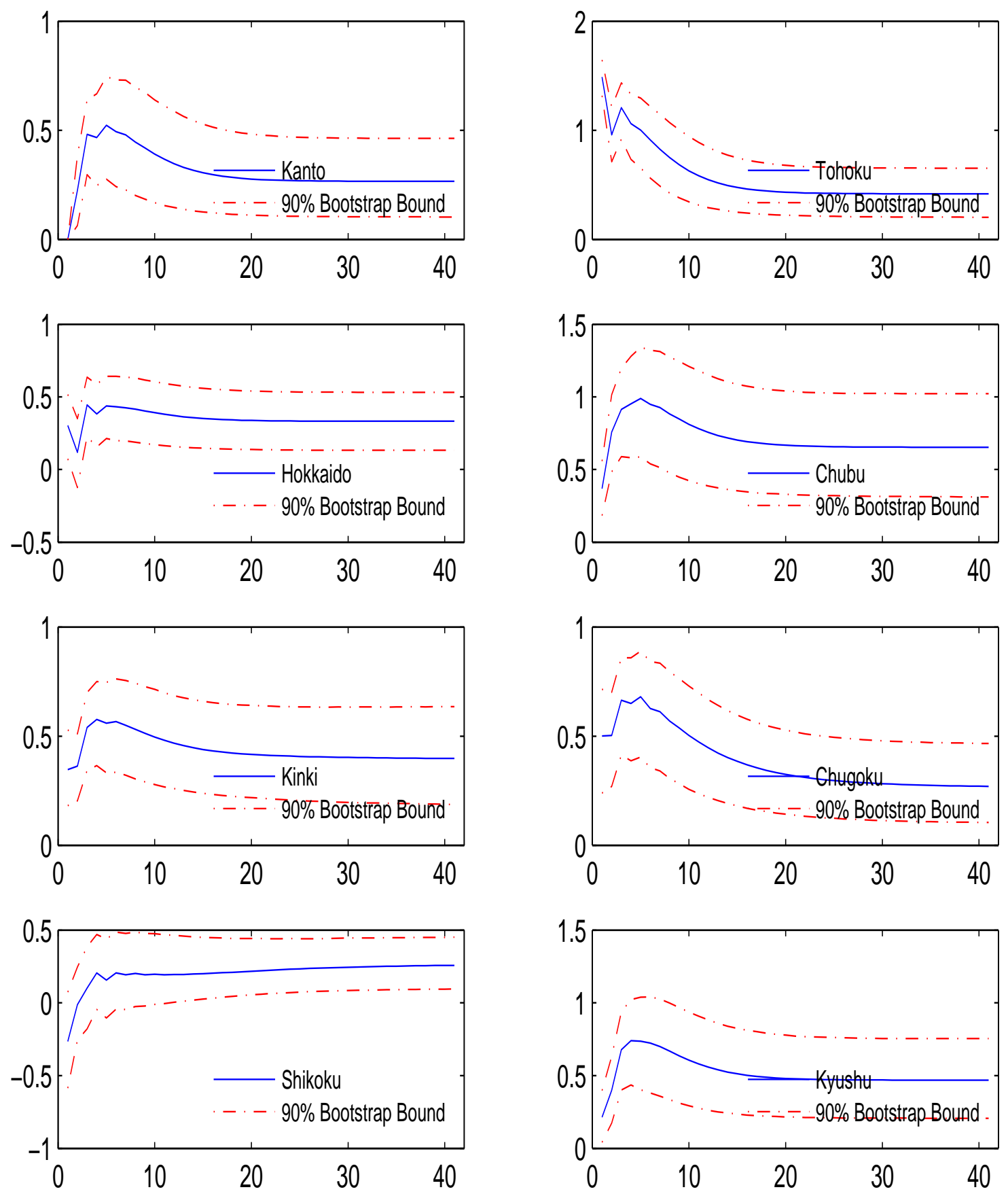
Figure 9: GIRF of IP by 1 unit shock on Tohoku

(a). Similarity Matrix

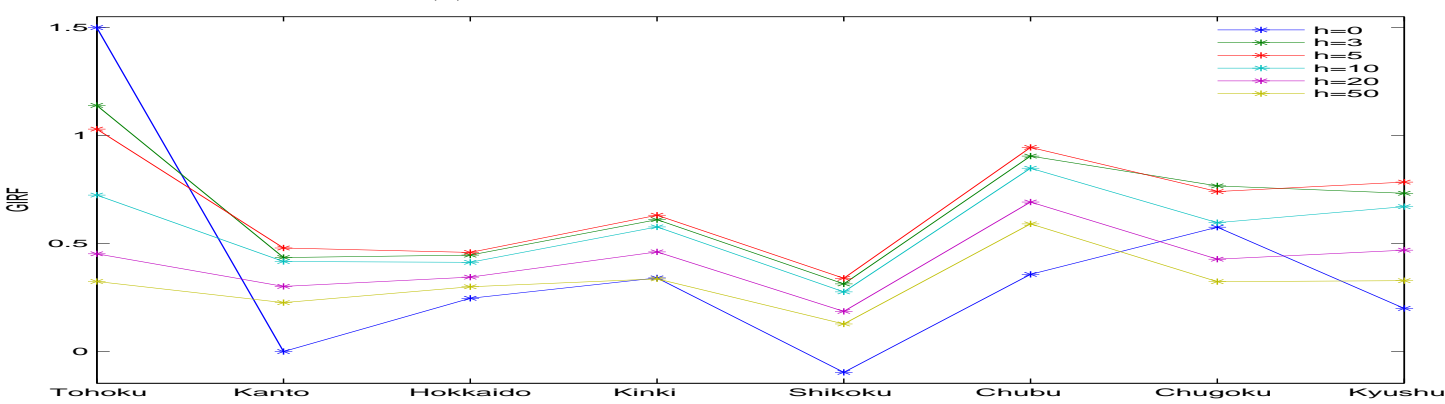

(b). Buying Matrix

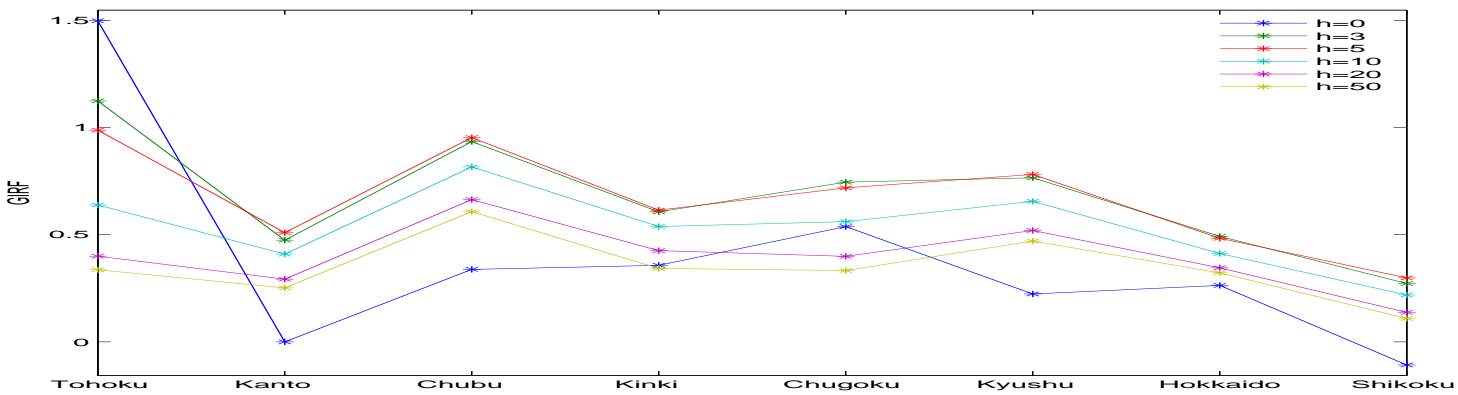

(c). Selling Matrix

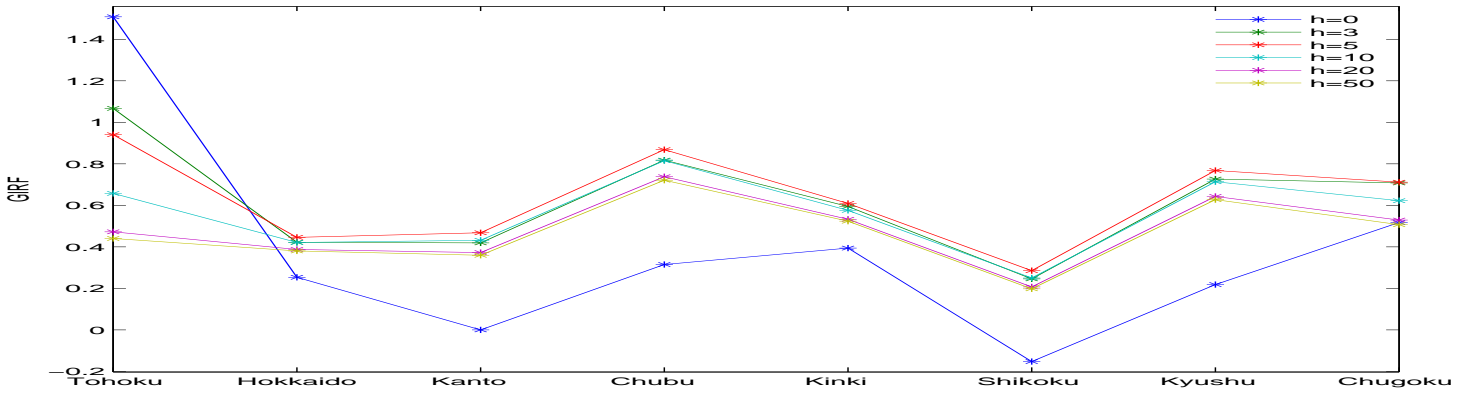

(d). Mutual Buying Matrix

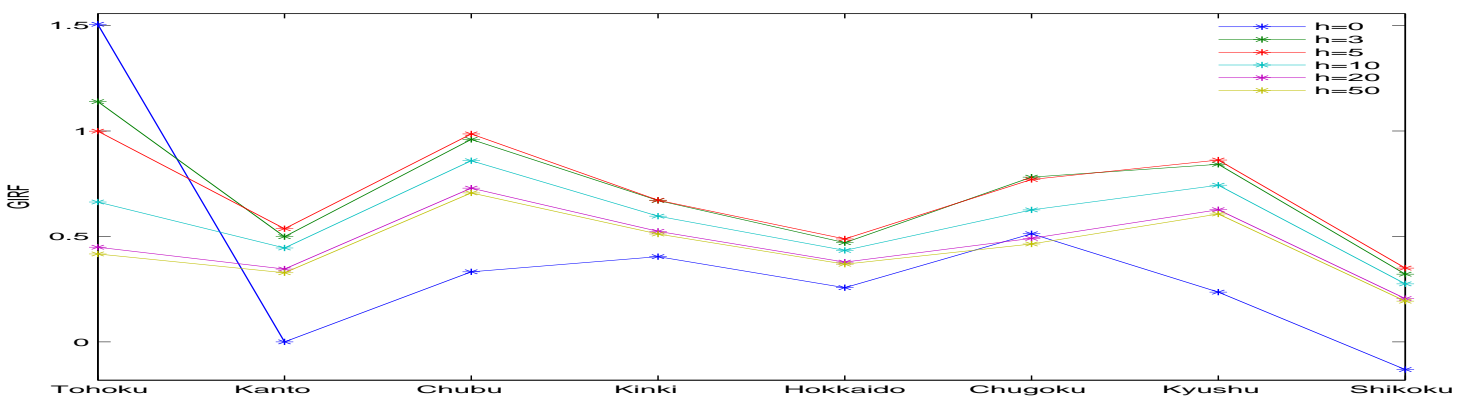

(e). Contiguity Matrix

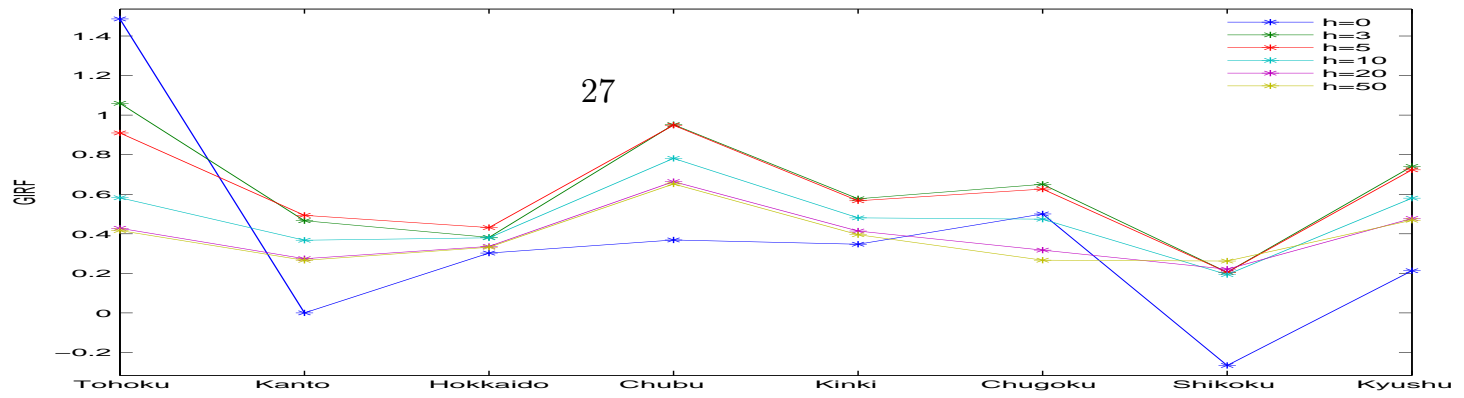

